\title{
Micromechanism and Kinetic Formulation of Vertically Aligned ZnO Nanorods Grown on Catalytic Bilayers
}

\author{
Dong-Hau Kuo and Jheng-Yu He \\ Department of Materials Science and Engineering, National Taiwan University of Science and Technology, Taipei 10607, Taiwan \\ Correspondence should be addressed to Dong-Hau Kuo, dhkuo@mail.ntust.edu.tw
}

Received 17 May 2012; Accepted 26 July 2012

Academic Editor: Renzhi Ma

Copyright ( $) 2012$ D.-H. Kuo and J.-Y. He. This is an open access article distributed under the Creative Commons Attribution License, which permits unrestricted use, distribution, and reproduction in any medium, provided the original work is properly cited.

\begin{abstract}
Vertically aligned $\mathrm{ZnO}$ nanorods were grown at $700^{\circ} \mathrm{C}$ for $2 \mathrm{~h}$ on sapphire substrates with catalysts in bilayer configurations of $\mathrm{Sn}$ (top)/Ni (bottom) and Sn/In, where the top layer is formed by sputtering and the bottom one is deposited by spin coating. The effects of bilayer catalysts on growth kinetics of nucleation and growth, growth micromechanism, and vertical alignment of growing $\mathrm{ZnO}$ nanorods have been investigated. The vertical alignment of the $\mathrm{Sn} / \mathrm{Ni}$-catalyzing $\mathrm{ZnO}$ nanorods is determined at the initial nucleation stage, where the nuclei are formed as regular candlestick-like platforms. The reason for the formation of the candlestick-like nuclei is due to the contribution of strain energy built in the underlying catalyst bilayers. The variations of axial and radial dimensions with growth duration for the growth of $\mathrm{ZnO}$ rods were explained and data fitting with the aids of kinetic growth equations, which are based upon the well-known ledge model for crystal growth from vapor and diffusion kinetics.
\end{abstract}

\section{Introduction}

Zinc oxide $(\mathrm{ZnO})$ is a direct bandgap semiconductor with a wide bandgap of $3.37 \mathrm{eV}$ and large exciton binding energy $(60 \mathrm{meV})$. This semiconductor has been attractive for optoelectronic applications in light-emitting diodes and laser diodes at room temperature. Nanometer scale, one-dimensional (1D) materials, such as nanowires, nanorods, and nanotubes, have become of great interest due to their potential applications in nanolaser, field emission devices, photovoltaic, piezoelectric transducers, photocatalysts, chemical, and biosensors, and so forth.

The vapor-phase growth of $1 \mathrm{D} \mathrm{ZnO}$ has been widely conducted with $\mathrm{Zn}$ and $(\mathrm{ZnO}+$ graphite) powders as reactants. The most uniform and vertically aligned (VA) $\mathrm{ZnO}$ nanorods with a diameter of $50-150 \mathrm{~nm}$ have been grown by using the carbothermal reaction above $850^{\circ} \mathrm{C}$ on Au catalystpatterned sapphire substrates with the aids of submicrometer sized polystyrene balls [1] and laser-hardening lithography technology $[2,3]$ or by using the $\mathrm{Zn}$ source at $750^{\circ} \mathrm{C}$ on sapphire substrates covered with a $c$ axis-oriented $\mathrm{ZnO}$ buffer layer [4]. Because no droplets on the tips of flat-ended nanorods have been observed, the self-catalytic growth mechanism or the vapor-solid mechanism is used to explain the growth behaviors. However, the self-catalytic mechanism needs to consider the oxidation of catalysts during the growth period. The vapor-liquid-solid growth mechanism has been applied for nanowires with dome-shaped droplets on its tips. The formation of catalyst droplets and its durability through the growth process without oxidation or nitridation are the major concerns.

Gold has been the most important and reliable catalyst for growing $1 \mathrm{D} \mathrm{ZnO}$, because it has demonstrated the capability to grow uniform and aligned nanorods. The preference of $\mathrm{Au}$ catalyst is related to its high-temperature stability in oxidizing atmosphere. Other catalysts such as $\mathrm{Ni}, \mathrm{Sn}, \mathrm{Cu}$, have also been examined, but their uniformity and size in diameter need to be improved. $\mathrm{ZnO}$ rods grown by thermal evaporation on the Ni-coated silicon had a large size of $300-350 \mathrm{~nm}$ in diameter [5]. By using Sn catalyst, a liquid Sn droplet was located on the tip of $\mathrm{ZnO}$ nanorods to assist the orientation-aligned growth $[6,7]$. Catalyst has been recognized as a requisite to perform the $1 \mathrm{D}$ catalyst-confined growth. In order to understand the growth micromechanisms, we ever used Au-containing bilayer catalysts of $\mathrm{Au} / \mathrm{Al}, \mathrm{Au} / \mathrm{Ni}$, and $\mathrm{Au} / \mathrm{In}$ to grow randomly oriented 
$\mathrm{ZnO}$ rods on silicon wafer substrates with diameters of $\sim 100,400$, and $800 \mathrm{~nm}$, respectively [8]. To make a further progress in order to grow well-aligned $\mathrm{ZnO}$ nanorods instead of micrometer sized and randomly oriented $\mathrm{ZnO}$ rods on the bilayer catalyst-covered substrates without using $\mathrm{Au}$ as a catalyst, we had investigated different unilayer or bilayer configurations made by mixed-solution coating, sputtering, polymer dispersant in coating solution, substrate etching techniques [9-11]. The one with the promising result is the $\mathrm{ZnO}$ rods grown on the Fe-covered [9] and $\mathrm{Sn} / \mathrm{Ni}$ bilayer substrates [11]. We have continued efforts on the growth of $\mathrm{ZnO}$ nanorods by using the bilayer configurations. There were few works to grow $\mathrm{ZnO}$ nanorods with a bilayer catalyst. With our variations in the bilayer configurations, we demonstrate in this paper with different growth modes and different micromechanisms.

From our systematic works, I have a better control in growing the well-aligned $\mathrm{ZnO}$ rods. Without the better growth control, the measurements of rod dimensions in repeated experiments with different growth durations will be very difficult and not reliable, which is the reason for the difficulty and limited reports in kinetic study. After we can provide reliable and controllable techniques to grow the uniform and vertically aligned $\mathrm{ZnO}$ nanorods with a size of $\sim 110 \mathrm{~nm}$ in diameter by utilizing the bilayer catalysts of $\mathrm{Sn} / \mathrm{Ni}$ and $\mathrm{Sn} / \mathrm{In}$, we intend to investigate the $\mathrm{ZnO}$ nanorods grown at different growth periods to explore the growth kinetics and the relations among the bilayer catalysts, the initial nucleation stage, and the subsequent growth stage. Kinetic growth equations are derived, which are based upon the variations of the axial and radial dimensions with the growth duration, and they are fitted well to our growth data. Some of works had measured the length/diameter changes with growth period, but only the interpretations were mentioned without rate equations to explain and fit their growth data individually in the axial and radial directions.

\section{Experimental}

$\mathrm{ZnO}$ nanowires were grown at $700^{\circ} \mathrm{C}$ for $2 \mathrm{~h}$ on the catalystcoated $\mathrm{Si}$ wafer or sapphire substrates by thermal evaporation under a mixture flow of 10 -sccm (standard cubic centimeter per minute) $\mathrm{O}_{2}$ and $200-\mathrm{sccm} \mathrm{N}_{2}$ with a $\mathrm{Zn}$ mixture of $\mathrm{Zn}$ and $\mathrm{ZnO}$ at a weight ratio of $1.0 \mathrm{~g}: 1.0 \mathrm{~g}$ or $1: 1$. The $\mathrm{Zn}$ mixture together with substrate was loaded on a graphite support. The preparation of catalyst layers involved spin coating and direct current (d.c.) sputtering. A similar experimental approach is listed in [9]. The spin coatings of $\mathrm{Sn}$, In, and $\mathrm{Ni}$ catalysts involved the $0.01 \mathrm{M}$ solutions of tin chloride, indium nitrate, and nickel nitrate, respectively, followed by pyrolysis at $650^{\circ} \mathrm{C}$ for $30 \mathrm{~min}$ and reduction at $850^{\circ} \mathrm{C}$ for $30 \mathrm{~min}$ in an $\left(\mathrm{Ar}+7 \% \mathrm{H}_{2}\right)$ mixed gas. Each pyrolyzed oxide had a film thickness of $\sim 0.1 \mu \mathrm{m}$. For d.c. sputtering, Sn, In, and Ni films were deposited at output powers of 20 and 70 watts for $1 \mathrm{~min}$ for coating Sn and $\mathrm{Ni}$, respectively, and of 5 watts for $3.5 \mathrm{~min}$ for depositing indium. These metallic catalyst layers had a thickness of $30-$ $60 \mathrm{~nm}$ for each. In addition to the single-layered catalysts, bilayer catalysts of $\mathrm{Sn} / \mathrm{Ni}$ and $\mathrm{Sn} / \mathrm{In}$ were also prepared. The bilayer catalysts were constituted by spin coating a bottom layer followed by sputtering a top layer. The symbol of $\mathrm{Sn} / \mathrm{Ni}$, as an example, represented a Sn-sputtered coating on top of a Ni-spin coated layer. After spin coating and pyrolysis of the Ni layer, the reduction reaction was executed after the Sn layer was sputtered on the nickel oxide. The sapphire substrates for the $\mathrm{Sn} / \mathrm{Ni}$ system were etched by a $0.1 \mathrm{M} \mathrm{NaOH}$ solution. The substrate for the Sn/In system was not etched. The etching did not change the vertical alignment but was beneficial for obtaining slender $1 \mathrm{D} \mathrm{ZnO}$. To study the growth kinetics, $\mathrm{ZnO}$ nanorods were grown at $700^{\circ} \mathrm{C}$ for different durations of $1 \mathrm{~min}, 5 \mathrm{~min}, 30 \mathrm{~min}$, and $120 \mathrm{~min}$ on $\mathrm{Sn} / \mathrm{Ni}$ and $\mathrm{Sn} / \mathrm{In}$ sapphire substrate. Before heating, the growth chamber was pumped down by mechanical pump. During the heating stage, the system was under argon and the $\mathrm{Zn}$ vapor generated as temperature approached $700^{\circ} \mathrm{C}$. When the temperature reached $700^{\circ} \mathrm{C}$, the mixed $\left(\mathrm{O}_{2}+\mathrm{N}_{2}\right)$ gas flowed into this system. Therefore, the oxide growth started at the $\mathrm{O}_{2}$-added stage. Scanning electron microscopes (SEM, JEOL JSM 6500F, Japan; Cambridge S360, UK) were used to observe the growth morphology. A field-emission scanning electron microscope (FESEM, JEOL JSM 6500F, Japan) was used to observe the growth morphology and to measure the rod dimensions in length and diameter. Phase identification, composition analysis, and microstructural characterization of nanowires were conducted by a transmission electron microscope (TEM, JEOL 3010, Japan) equipped with energy dispersive spectroscopy (EDS). Room-temperature photoluminescence (PL) measurements were performed using a $325 \mathrm{~nm} \mathrm{He}-\mathrm{Cd}$ laser as the excitation source.

\section{Results}

3.1. ZnO Growth on Catalytic Unilayers. Figure 1 shows SEM images of one-dimensional $\mathrm{ZnO}$ grown at $700^{\circ} \mathrm{C}$ for $2 \mathrm{~h}$ on (a), (b) Sn, (c), (d) In, and (e), (f) Ni (a), (c), (e) sputter or (b), (d), (f) spin coated silicon wafer substrates by thermal evaporation with a $\mathrm{Zn}$ mixture of $\mathrm{Zn}$ and $\mathrm{ZnO}$ in a weight ratio of $1.0 \mathrm{~g}: 1.0 \mathrm{~g}$. The $\mathrm{Sn}$-catalyzing $1 \mathrm{D} \mathrm{ZnO}$ was in the form of nanowires with smaller diameters of $100 \mathrm{~nm}$ (Figure 1(a)) and $200 \mathrm{~nm}$ (Figure 1(b)). The In-catalyzing growth contained nonuniform $\mathrm{ZnO}$ crystals including rods of $200-300 \mathrm{~nm}$ in size and larger leaf-like crystals (Figures $1(\mathrm{c})$ and $1(\mathrm{~d})$ ). The Ni-catalyzing $1 \mathrm{D} \mathrm{ZnO}$ grown on $\mathrm{Si}$ wafer substrates were in the form of inclined and hexagonalshaped rods with a larger diameter of $800 \mathrm{~nm}-1.5 \mu \mathrm{m}$ for those spin coated (Figure 1(f)) and in the form of leafs with a large dimension in $600 \mathrm{~nm}-1.2 \mu \mathrm{m}$ for those sputtered (Figure 1(e)). There is no difference for $\mathrm{ZnO}$ from the $\mathrm{Sn}$ catalyst, which can be attributed to its melt state at different catalyst size. However, the difference in the $\mathrm{ZnO}$ shape from the $\mathrm{Ni}$ catalyst can be related to the catalyst size, which in the solid state has led to different crystallinities. Catalysts of Sn, In, Ni spin coated with nitrate or chloride solutions can be reduced to form metallic droplets for Sn and Ni but it remains as an oxide layer for In catalysts. No matters of metallic indium or indium oxide, the grown $\mathrm{ZnO}$ had no 


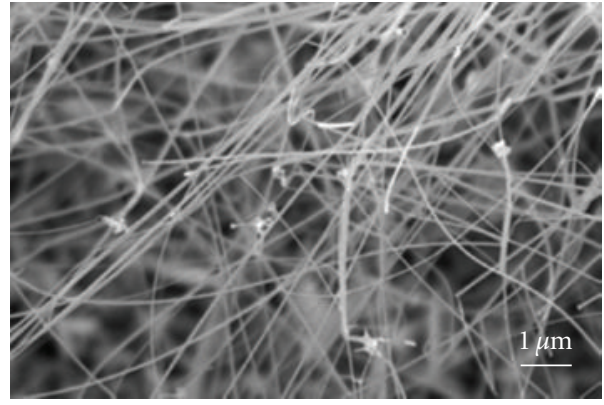

(a)

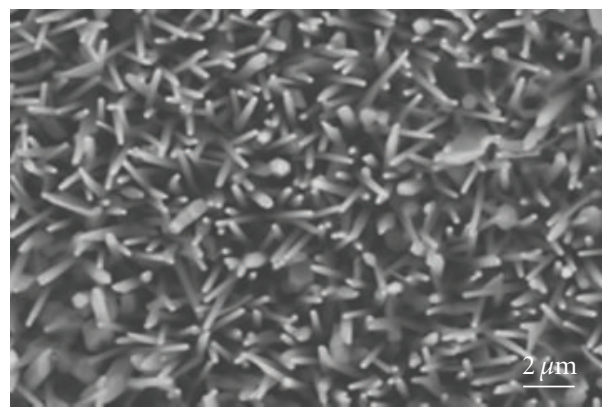

(c)

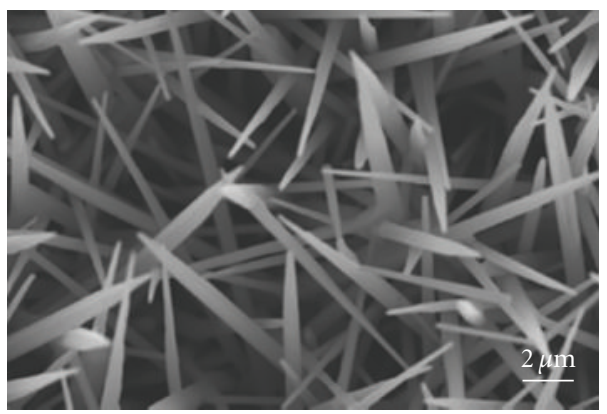

(e)

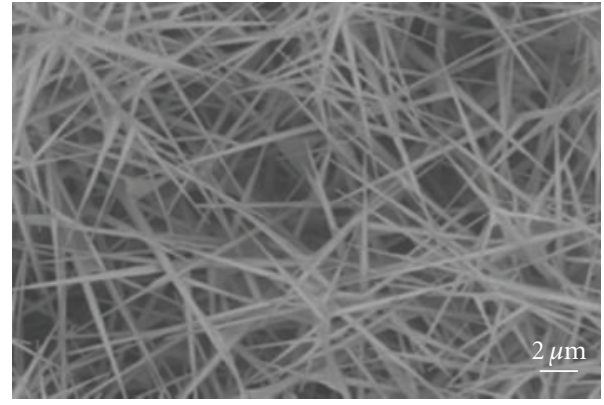

(b)

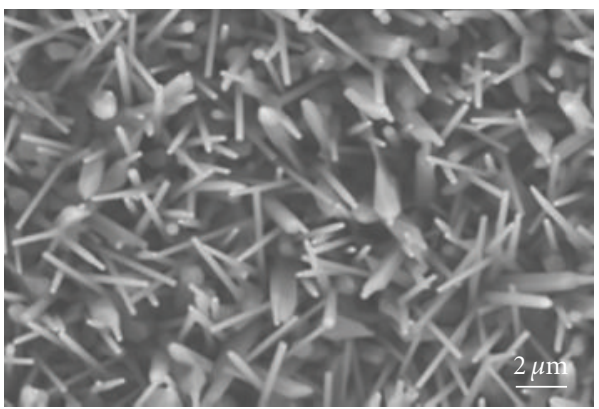

(d)

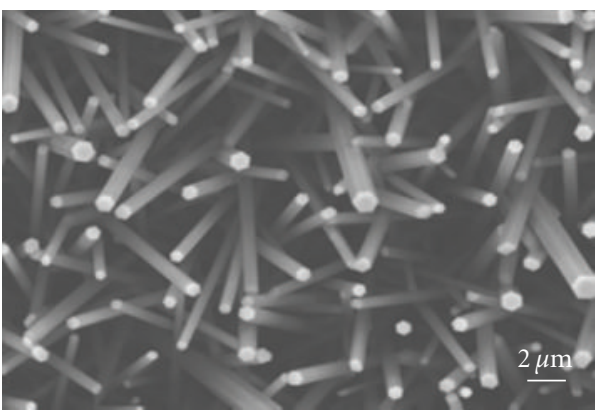

(f)

Figure 1: SEM images of one-dimensional $\mathrm{ZnO}$ grown at $700^{\circ} \mathrm{C}$ for $2 \mathrm{~h}$ on (a), (b) Sn, (c), (d) In, and (e), (f) Ni (a), (c), (e) sputter- or (b), (d), (f) spin coated silicon wafer substrates by thermal evaporation with a $\mathrm{Zn}$ mixture of $\mathrm{Zn}$ and $\mathrm{ZnO}$ in a weight ratio of $1.0 \mathrm{~g}: 1.0 \mathrm{~g}$.

big differences for the sputtered and the spin coated ones. From these experiments, the Sn catalyst generates the finest nanowires and the spin coated $\mathrm{Ni}$ catalyst favors to form $\mathrm{ZnO}$ nanorods with a hexagonal cross-section. However, the size of these hexagonal-shaped $\mathrm{ZnO}$ was in a submicrometer scale. 1D $\mathrm{ZnO}$ rods grown with the $\mathrm{Ni}$ catalyst have constantly suffered the problem of large diameters [5].

3.2. $\mathrm{ZnO}$ Growth on Catalytic Bilayers. Two types of bilayer catalysts used to assist the $1 \mathrm{D} \mathrm{ZnO}$ growth include $\mathrm{Sn} / \mathrm{Ni}$ and $\mathrm{Sn} / \mathrm{In}$. Figure 2 displays surface morphologies of $\mathrm{ZnO}$ nanorods grown at $700^{\circ} \mathrm{C}$ for (b) $1 \mathrm{~min}$, (c) $5 \mathrm{~min}$, (d) $30 \mathrm{~min}$, and (e) $120 \mathrm{~min}$ on $\mathrm{Sn}$ sputter/Ni spin coated sapphire substrates. After growing for $1 \mathrm{~min}$, no 1D formed and only nuclei were observed. $\mathrm{ZnO}$ nanorod arrays with a hexagonal cross-section had formed with a length of 0.4 $\pm 0.1 \mu \mathrm{m}$ and a diameter of $100 \pm 20 \mathrm{~nm}$ in $5 \mathrm{~min}$ from pyramid platforms, which behaved like a candle rod sits on a candlestick. These pyramid platforms were examined at higher magnifications, as can be seen in the inset of Figure 2(c). With increasing growth time, nanorods increase apparently on its length but not on its diameter. After a 2$\mathrm{h}$ growth duration, the grown $\mathrm{ZnO}$ rods had a length of 30 $\pm 10 \mu \mathrm{m}$ and a diameter of $110 \pm 25 \mathrm{~nm}$. The image of asfabricated $\mathrm{Sn} / \mathrm{Ni}$ bilayer catalyst, after pyrolysis at $650^{\circ} \mathrm{C}$ for $30 \mathrm{~min}$ and reduction at $850^{\circ} \mathrm{C}$ in an $\mathrm{Ar}-5 \% \mathrm{H}_{2}$ mixture gas for $30 \mathrm{~min}$, is shown in Figure 2(a). Before the $\mathrm{ZnO}$ growth, the $\mathrm{Sn} / \mathrm{Ni}$ bilayer catalyst had become spheroidal. After the 1-min growth, the spheroidal catalysts disappear and the substrates were covered with the oxidized $\mathrm{Zn}$-covering layers. The $2 \mathrm{D}$ growth on $1 \mathrm{D}-\mathrm{ZnO}$ had been observed by metalorganic chemical vapor deposition [12].

Figure 2(f) shows the PL spectra of the VA-ZnO nanorods shown in Figure 2(e). From the PL spectra, it can be seen that the vertically aligned $\mathrm{ZnO}$ nanorods only show a sharp and strong peak at approximately $383.3 \mathrm{~nm}(3.24 \mathrm{eV})$, which corresponds to the near-band-edge peak that is 


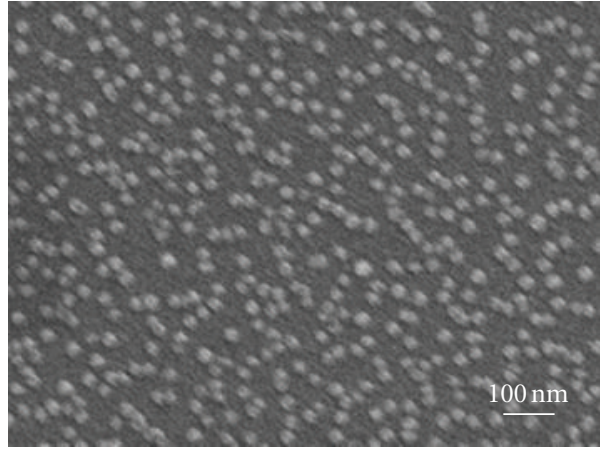

(a)

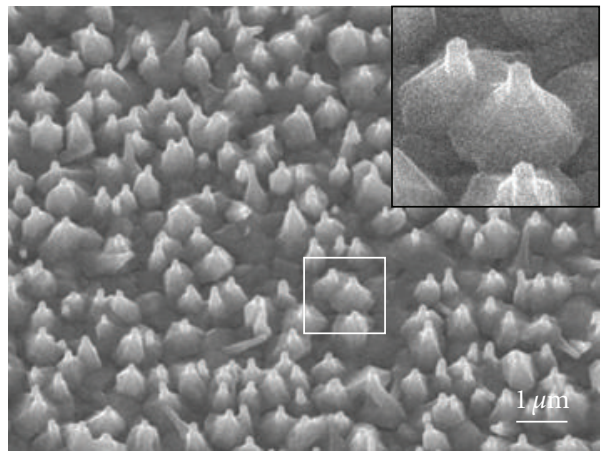

(c)

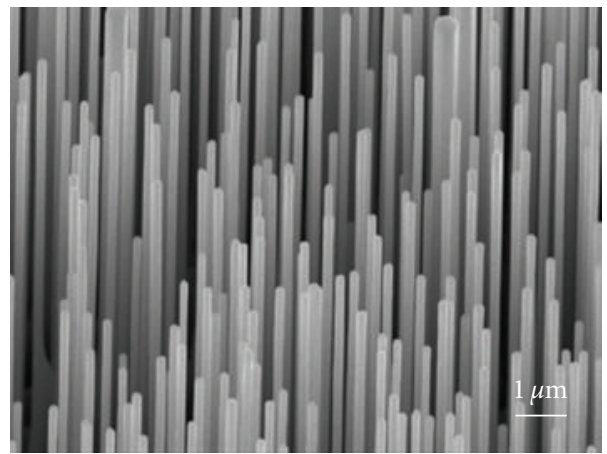

(e)

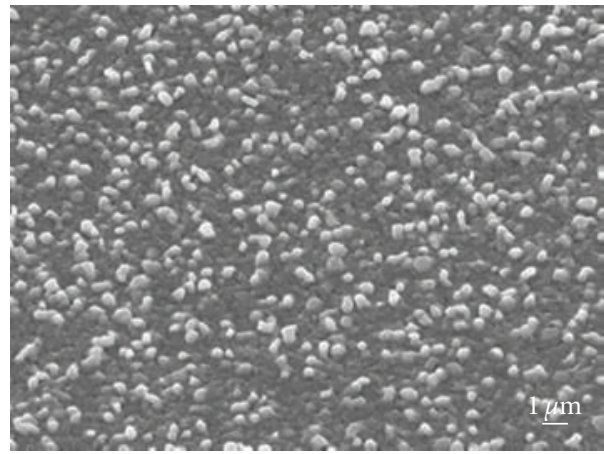

(b)

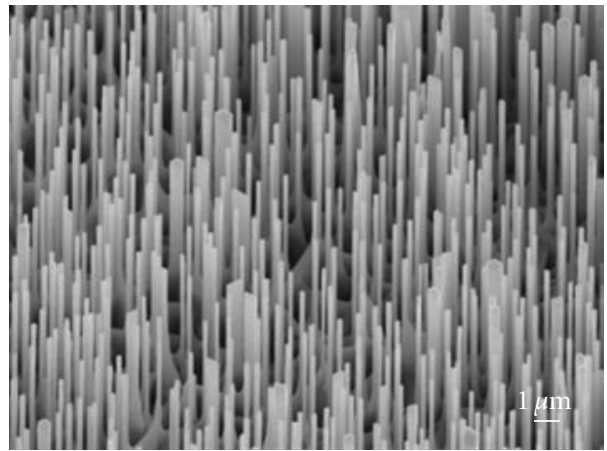

(d)

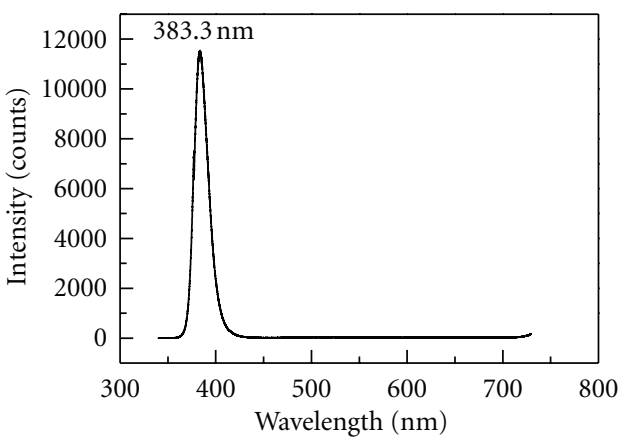

(f)

Figure 2: Surface morphologies of $\mathrm{ZnO}$ nanorods grown at $700^{\circ} \mathrm{C}$ for (b) $1 \mathrm{~min}$, (c) $5 \mathrm{~min}$, (d) $30 \mathrm{~min}$, and (e) $120 \mathrm{~min}$ on $\mathrm{Sn}$ sputter-/Ni spin coated sapphire substrates by thermal evaporation with a Zn mixture of $\mathrm{Zn}$ and $\mathrm{ZnO}$ in a weight ratio of $1: 1$. (a) SEM image of Sn sputter-/Ni spin coated bilayer catalysts after pyrolysis at $650^{\circ} \mathrm{C}$ for $30 \mathrm{~min}$ and reduction at $850^{\circ} \mathrm{C}$ in a $\mathrm{Ar}-5 \% \mathrm{H}_{2}$ mixture gas for 30 min. (f) Photoluminescence spectra for the vertically aligned $\mathrm{ZnO}$ nanorods in (e). The substrates were etched by a $0.1 \mathrm{M} \mathrm{NaOH}$ solution for $15 \mathrm{~s}$. The inset in (c) was enlarged from the white square-selected area.

responsible for the recombination of free excitons through an exciton-exciton collision process [13-15]. A full width at half maxima value of $145 \mathrm{meV}$ for this excitonic emission was obtained [16]. The appearance of a sharp and strong near-band-edge emission in the UV region without any deep level emission in the visible region indicates that the asgrown $\mathrm{ZnO}$ nanorods showed good crystallinity with a good optical property and few structural defects such as oxygen vacancies and interstitials of zinc. Therefore, based upon the bilayer catalyst-assisting growth, VA-ZnO nanorods with a good ultraviolet emission quality can be grown from pyramidal platforms or nuclei with parallel (0001) planes to the substrate surface.
Figure 3 displays surface morphologies of $\mathrm{ZnO}$ nanorods grown at $700^{\circ} \mathrm{C}$ for (b) $1 \mathrm{~min}$, (c) $5 \mathrm{~min}$, (d) $30 \mathrm{~min}$, and (e) $120 \mathrm{~min}$ on $\mathrm{Sn} / \mathrm{In}$ bilayer-coated sapphire substrates. The Sn/In catalysts remained as a layer on substrates (Figure 3(a)). The sputtered Sn layer inhibited by the underlying $\mathrm{In}_{2} \mathrm{O}_{3}$ layer did not become spheroidal after $850^{\circ} \mathrm{C}$ annealing. $\mathrm{ZnO}$ nuclei formed after the 1-min growth duration (Figure 3(b)). The $\mathrm{ZnO}$ nanorods directly grown from the catalytic buffer layer had a length of $0.75 \pm 0.25 \mu \mathrm{m}$ and a diameter of $250 \pm 30 \mathrm{~nm}$ in $5 \mathrm{~min}$ without the platform nuclei available (Figure 3(c)). With the increase in the growth duration, the length and diameter of nanorods apparently increased. After a 2-h growth duration, the grown $\mathrm{ZnO}$ 


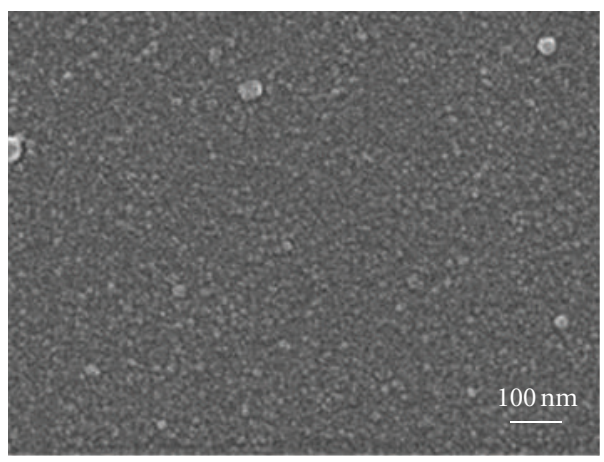

(a)

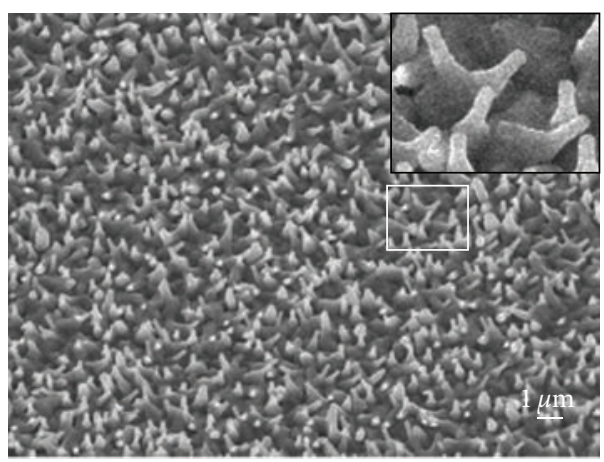

(c)

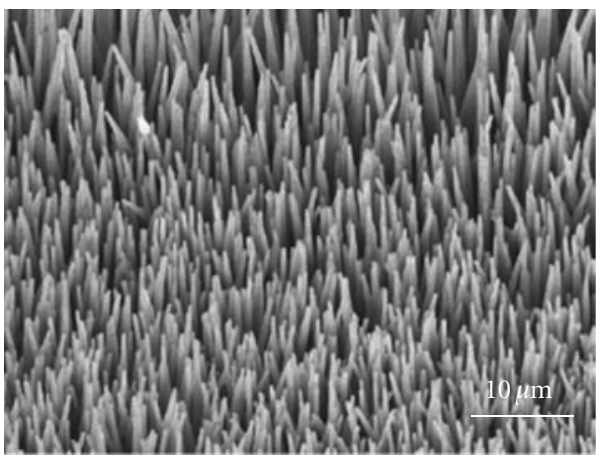

(e)

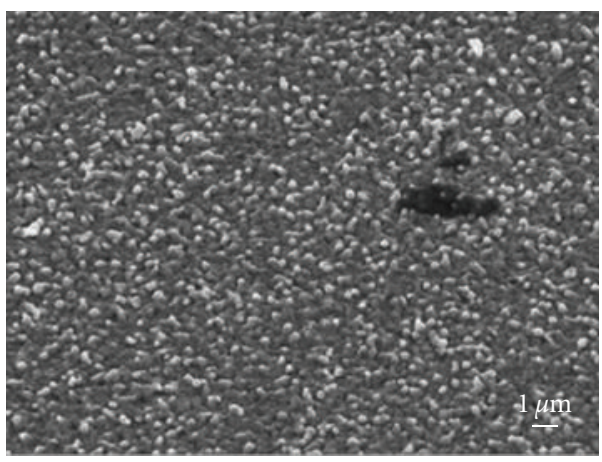

(b)

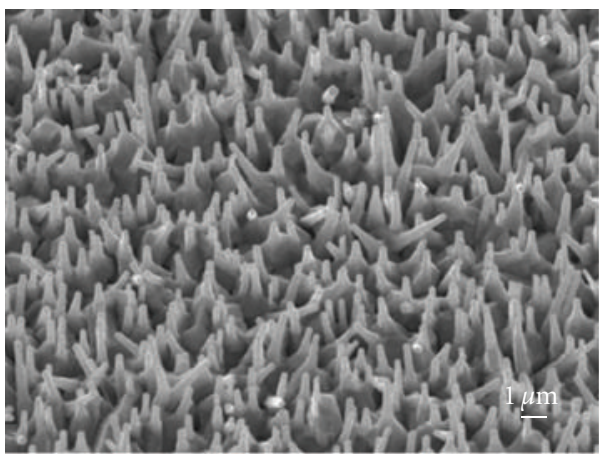

(d)

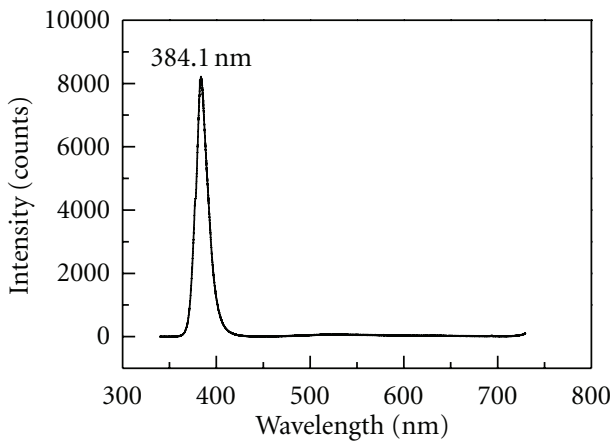

(f)

FIGURE 3: Surface morphologies of $\mathrm{ZnO}$ nanorods grown at $700^{\circ} \mathrm{C}$ for (b) $1 \mathrm{~min}$, (c) $5 \mathrm{~min}$, (d) $30 \mathrm{~min}$, and (e) $120 \mathrm{~min}$ on Sn sputter-/In spin coated sapphire substrates by thermal evaporation with a $\mathrm{Zn}$ mixture of $\mathrm{Zn}$ and $\mathrm{ZnO}$ in a weight ratio of $1: 1$. (a) SEM image of Sn sputter-/In spin coated bilayer catalysts after pyrolysis at $650^{\circ} \mathrm{C}$ for $30 \mathrm{~min}$ and reduction at $850^{\circ} \mathrm{C}$ in an $\mathrm{Ar}-5 \% \mathrm{H}_{2}$ mixture gas for 30 min. (f) Photoluminescence spectra for the vertically aligned $\mathrm{ZnO}$ nanorods in (e). The inset in (c) was enlarged from the white square-selected area.

rods had a length of $25 \pm 5 \mu \mathrm{m}$ and a diameter of $400 \pm$ $55 \mathrm{~nm}$ (Figure 3(e)). Although the Sn/In-catalyzing $\mathrm{ZnO}$ rods had a hexagonal shape in cross-section, but these rods were not aligned. The inset in Figure 3(c) shows an enlarged image to observe the initial growth stage of $\mathrm{ZnO}$ nanorods. There were no larger, well-defined, and isolated pyramid platforms spreading on the $\mathrm{ZnO}$-covering substrate surface. Figure 3(f) shows the PL spectra of the VA0- $\mathrm{ZnO}$ nanorods shown in Figure 3(e). The aligned $\mathrm{ZnO}$ nanorods display a sharp and strong peak at approximately $384.1 \mathrm{~nm}$ $(3.23 \mathrm{eV})$. This nanorod showed a similar result in photoluminescence measurement as that shown for $\mathrm{ZnO}$ obtained from the $\mathrm{Sn} / \mathrm{Ni}$ catalyst (Figure 2(f)). The similar performance indicates the different catalyst configurations only change the growth behaviors but do not introduce growth defects.

3.3. Dimensional Changes in the Axial and Radial Directions. The growth kinetic study of $1 \mathrm{D} \mathrm{ZnO}$ is executed by measuring the changes of the axial and radial dimensions with the growth duration. Figures 4(a) and 4(b) show the variations of the diameter and length of $\mathrm{ZnO}$ nanorods grown at $700^{\circ} \mathrm{C}$ for different durations of 1, 5, 30, $120 \mathrm{~min}$ on (a) Sn/Niand (b) $\mathrm{Sn} / \mathrm{In}$-coated sapphire substrates. Both of the systems 


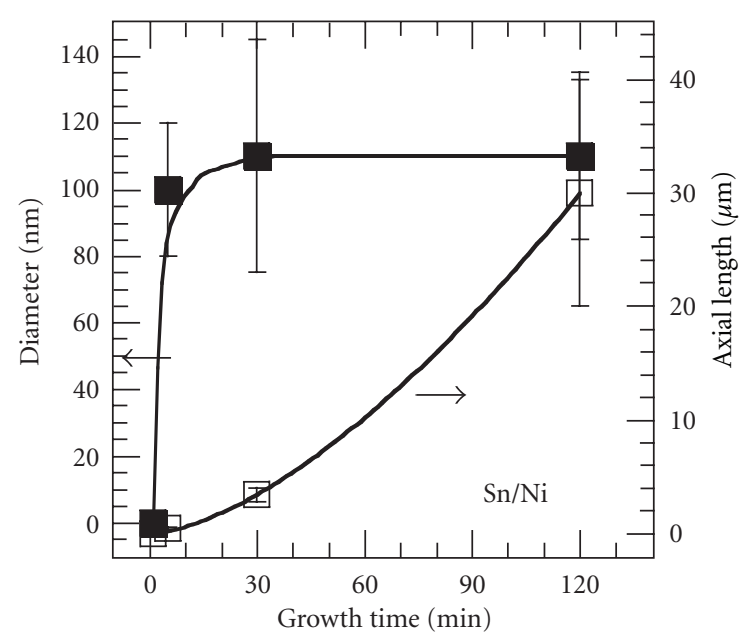

(a)

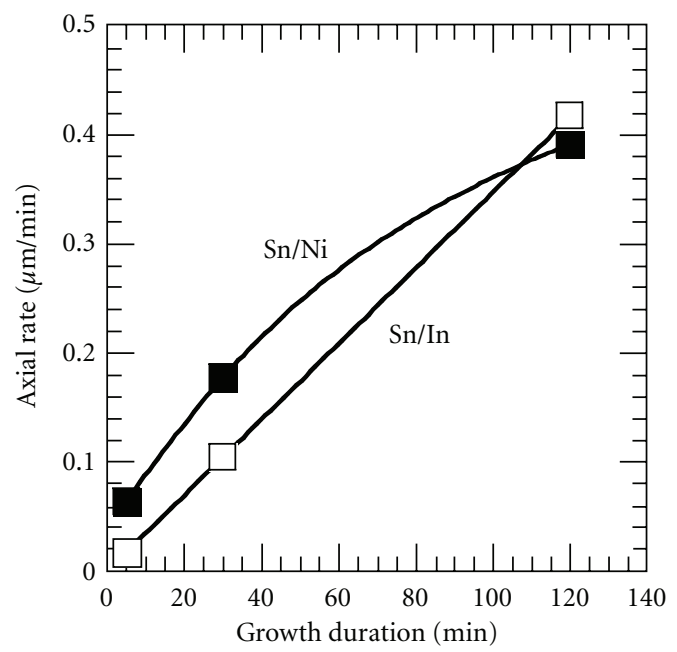

(c)

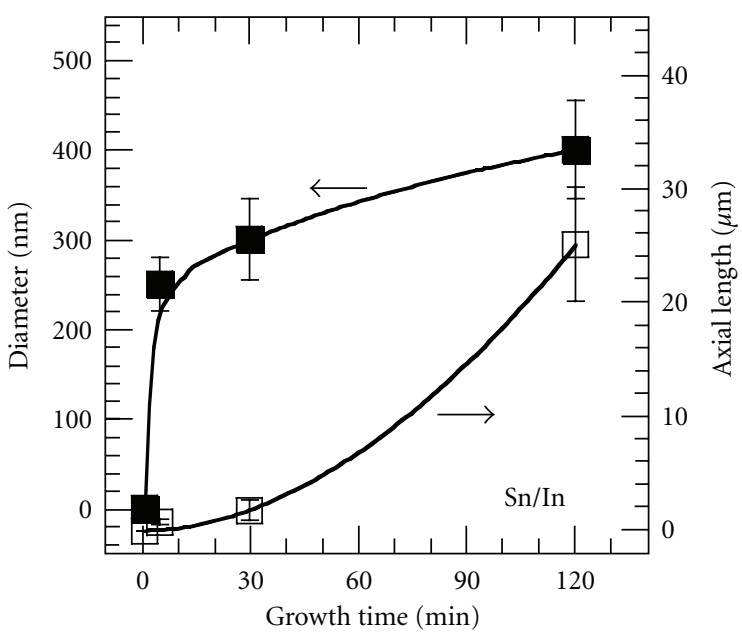

(b)

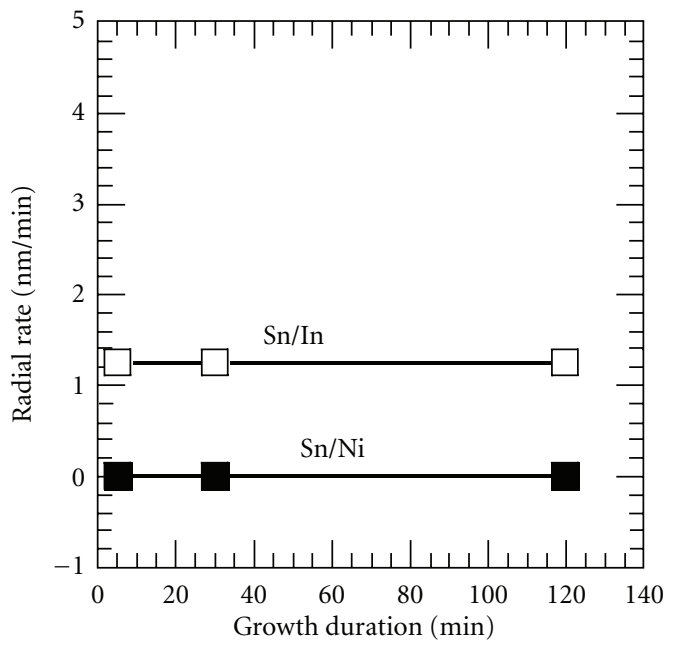

(d)

Figure 4: Growth behaviors in terms of the diameter and length of $\mathrm{ZnO}$ nanorods grown at $700^{\circ} \mathrm{C}$ for different durations of $1,5,30,120$ min on (a) Sn/Ni- and (b) Sn/In-coated sapphire substrates by a thermal evaporation-oxidation method with a $\mathrm{Zn}$ mixture of $\mathrm{Zn}$ and $\mathrm{ZnO}$ in a weight ratio of $1: 1$. The variations of axial and radial rates, obtained by curve fitting the 5-, 30, and 120-min data followed by retrieving from the derivatives of the best-fitting equations, with growth duration are shown in (c) and (d), respectively.

display a slight different trend. The $\mathrm{Sn} / \mathrm{Ni}$-catalyzing rods after growing for $5 \mathrm{~min}$ and $2 \mathrm{~h}$ have diameters of $100 \pm$ 20 and $110 \pm 25 \mathrm{~nm}$, respectively, and lengths of $0.4 \pm 0.1$ and $30 \pm 10 \mathrm{um}$. The stage for the first few minutes belongs to nucleation. The growth stage began apparent after a 5minute growth period. The axial and radial growth rates can be derived at different periods, excluding the nucleation stage, as shown in Figures 4(c) and 4(d), by curve fitting the wire length-growth duration plot, followed by retrieving from the derivatives of the curve-fitting equations to obtain growth rates at the durations of 5, 30, and $120 \mathrm{~min}$. This approach needs to be emphasized, because the growth rate is not obtained from the measured length divided by our growth duration. The conventional approach is related to an average growth rate during a growth period, but our approach is to obtain an instantaneous rate. For the $\mathrm{Sn} / \mathrm{Ni}$ system, the lengthening rate was proportional to the time exponent of
$1 / 2$ and the thickening rate is zero. The lengthening and thickening rates were proportional to the time exponents of 1 and 0 for the $S n / I n$ system.

\section{Discussion}

4.1. $\mathrm{ZnO}$ Growth. From the previous experimental data, two comparable systems of $\mathrm{Sn} / \mathrm{Ni}$ and $\mathrm{Sn} / \mathrm{In}$ have been obtained. The $\mathrm{Sn} / \mathrm{Ni}$ system has grown the vertically aligned $\mathrm{ZnO}$ nanorods from the regularly aligned candlestick-like nuclei. The growth of $\mathrm{ZnO}$ rods from this system is a nucleusconfined growth. It only grows in the axial direction. The $\mathrm{Sn} / \mathrm{In}$ system has grown the incompletely aligned rods from the $\mathrm{ZnO}$-covering buffer layer. It does not show the apparent nuclei, as the candlestick-like nuclei do. These rods grow in both the axial and radial directions. By using the apparently 

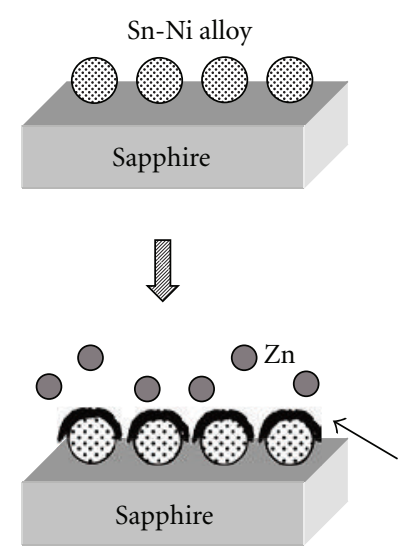

(ii)

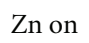

Sn-Ni-Zn or $\mathrm{Sn}-\mathrm{Zn}$

Candlestick-like nuclei formed

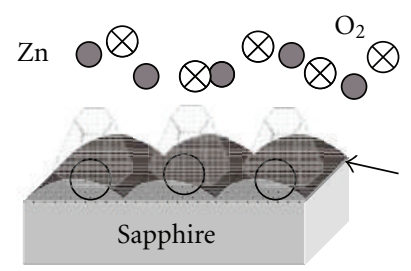

Only grow in the axial direction

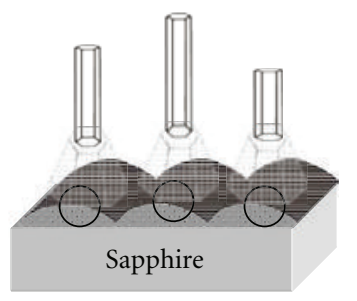

(a)

(i)

(iii) $\mathrm{ZnO}$ Layer

(iv)
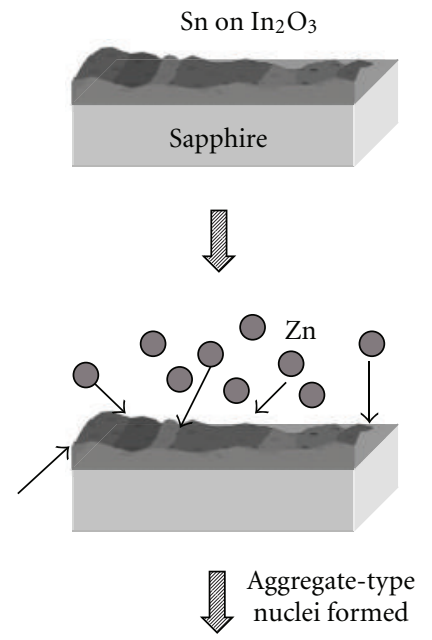

Massif-like

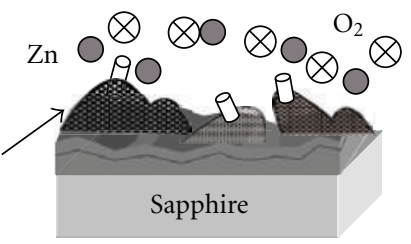

Grow in the axial and radial direction

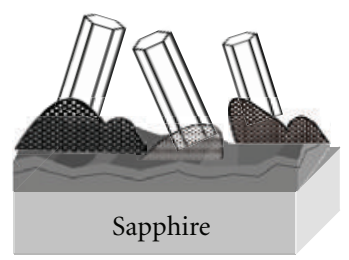

(b)

FIGURE 5: Schematic growth micromechanisms for (a) vertically aligned ZnO nanorod array grown on the Sn sputter/Ni spin coated sapphire substrates and for (b) slightly slant $\mathrm{ZnO}$ nanorods grown on the $\mathrm{Sn} / \mathrm{In}$ coated substrates.

different systems for comparative purposes, the reasons for the growth behavior and dimensional change need to be explained and embodied by a formulated equation.

4.2. Our Proposed Growth Micromechanisms. From the observations of Figures 2 and 3, it is observed that the style of nuclei formed at the early stage of nucleation determines the vertical alignment of $1 \mathrm{D} \mathrm{ZnO}$. Figure 5 shows the schematic diagrams of the growth micromechanisms of the bilayercatalyzing $\mathrm{ZnO}$ nanorods with the (a) vertically aligned and (b) slightly slant modes. The nuclei can be easily distinguished in the $\mathrm{Sn} / \mathrm{Ni}$ system, where the flat-end pyramidshaped islands form as candlestick-like platforms to provide the sites for growing $\mathrm{ZnO}$ nanorods with a hexagonal crosssection. On the other hand, the $\mathrm{Sn} / \mathrm{In}$ system does not show the well-defined nuclei or the candlestick-like platforms and has grown slightly slant $\mathrm{ZnO}$ nanorods directly from the large-grained $\mathrm{ZnO}$ buffer layer by aggregating the adsorbed adatoms through a short-range diffusion to form the nuclei. Briefly speaking, the $\mathrm{Sn} / \mathrm{Ni}$ system has the platforms on the massif-like $\mathrm{ZnO}$-covering layer but the $\mathrm{Sn} / \mathrm{In}$ system only has the $\mathrm{ZnO}$ rods grown from the massif-like layer. The different nucleation behaviors can lead to the different inclination in alignment. The obvious reason for the differences of these two systems is related to the different components of nickel in the $\mathrm{Sn} / \mathrm{Ni}$ system and indium in the Sn/In system. For the as-fabricated catalyst images in Figures 2(a) and 3(a), isolated catalyst droplets have formed in the $\mathrm{Sn} / \mathrm{Ni}$ system, but it is not the case for the Sn/In system (Figure 5(i)). The nonreducible $\mathrm{In}_{2} \mathrm{O}_{3}$ films inhibit the spheroidization of metallic Sn in the Sn/In system (Figure 5(b-i)). Before oxygen enters the reactor at $700^{\circ} \mathrm{C}$, zinc vapor liberates during the heating cycle. The vaporized $\mathrm{Zn}$ will condense and cover on substrates (Figure 5(ii)), react with the spheroidal catalysts (Figure $5(\mathrm{a}-\mathrm{ii})$ ), and be oxidized once oxygen is introduced (Figure 5(a-iii)) [17]. For the Sn/Ni system, the 
ZnO buffer layers embedded inside with reacted spheroidal catalysts are composed of large grains and favor to nucleate flat-end or (0001) plane-oriented pyramid platforms. The flat ends of those platforms orient parallel to the (0001) plane-oriented sapphire substrates in order to establish the well-aligned nanorods. After a 1-minute growth period (Figure 2(b)), the nuclei or platforms are not obvious. After a 5-minute growth period, the pyramidal nuclei have formed with protruded nanorods of $0.4 \mu \mathrm{m}$ in length. It can be induced that the nucleation step is accomplished within the first five minutes. After a 2-h growth duration, our nucleus platforms behave as candlesticks regularly sitting on the massif-like table ready for growing VA-ZnO nanorods with a diameter of $\sim 110 \mathrm{~nm}$.

For the $\mathrm{Sn} / \mathrm{In}$ system, the $\mathrm{ZnO}$ buffer layers underlying with flat $\mathrm{Sn} / \mathrm{In}_{2} \mathrm{O}_{3}$ catalyst layers (Figures 5(b-ii) and 3(b)). Nucleation occurs randomly and does not form the flatend pyramid platforms. Once the nuclei grow to a critical size, the $\mathrm{ZnO}$ nanorods are directly grown from the massiflike $\mathrm{ZnO}$ layers in an inclined orientation via the reactant adsorption from vapor, surface diffusion of adatoms, zincoxygen reactions, and the desorption for the surplus reactants (Figure 5(b-iii)). As the $\mathrm{ZnO}$ growth continues, the rods increase its dimensions in length and diameter (Figure 5(b-iv)). However, the formation of isolated catalyst droplets cannot guarantee the vertical alignment of $\mathrm{ZnO}$ nanorods. To have regularly aligned $\mathrm{ZnO}$ nanorods, the formation of the candlestick-like platforms is the critical factor. Therefore, the choice of the catalyst combination is very important, which can lead to different catalyst properties, reactions, and stress states. Based on the nucleation and growth theory for crystal growth, the extra built-in strain energy in the $\mathrm{Sn} / \mathrm{Ni}$ system assists nucleation by overcoming the formation energy of pyramidal nuclei. There is no sufficient built-in strain energy for the Sn/In system due to the softness of $\mathrm{Sn}$ metal in the form of flat layer. Growth mechanisms of randomly oriented $1 \mathrm{D} \mathrm{ZnO}$ with nanopen-, nanonail-, or nanopencil-like structure on pyramids have been proposed in literatures, however, their pyramids had a comparatively large dimension to form the pen-like shape $[18,19]$. Kim et al. have been aware that the nanosheets with several facet planes play a significant role in the evolution of ultraslim and vertical $\mathrm{ZnO}$ nanowire arrays [20]. However, their nanosheets are similar to the previously proposed selfcatalyzing $\mathrm{ZnO}$ buffer layers.

4.3. Kinetics and Kinetic Model. Our candlestick-like nuclei restrict the thickening of $\mathrm{ZnO}$ nanorods. When the axial dimensions of $\mathrm{ZnO}$ rods increase exponentially with the growth duration, their radial dimensions do not change for the $\mathrm{Sn} / \mathrm{Ni}$ system but have a big change for the $\mathrm{Sn} / \mathrm{In}$ system (Figure 4(b)). The irrelevance of our radial dimension in the $\mathrm{Sn} / \mathrm{Ni}$ system with growth time is similar with the growth of carbon nanotubes (CNTs) and can be attributed to the nucleus-confined growth behavior. The reported diameters of $1 \mathrm{D} \mathrm{ZnO}$ increased with growth time [21, 22]. Tsao et al. reported a linear relation. For the axial dimension, it increases fast but levels off at long durations for CNTs [23]. A linear relation between the length of nanowires and growth time for $1 \mathrm{D} \mathrm{ZnO}$ has been reported $[21,24]$. Reports with experimental growth data in the axial and radial directions simultaneously changed with growth duration are rare. The trends of rod length or diameter in the growth kinetics have been mentioned, but the explanations and data fitting with kinetic equations are much difficult. What the relevance is between the changes of rod length and diameter needs more understanding, regardless to say the data fitting for the rod length and diameter together with kinetic equations. However, we will use kinetic equations to fit and explain the growth rates in radial and axial directions together. The systematical dimension measurements at different durations for kinetic understanding are our major approach to probe the growth kinetic problems. This work is totally different from our previous work on the developments of aligned and well-controlled $\mathrm{ZnO}$ rods, but they provide the basis for our progress in kinetics [8-11].

To analytically formulate the vapor-solid growth rates, the kinetic of the well-known ledge model (Figure 6(a)) and the surface diffusion (Figure 6(b)) needs to be considered $[25,26]$. Although this mechanism has been well developed, there are no reported data referring or fitting to the equations derived from such a ledge mechanism. The reactants from vapors will gas-phase diffuse through a boundary layer to surface and become adatoms. The adatoms will propagate on surface through surface diffusion to execute reactions and find stable sites to reside. There are two directions on the step ledge, one is for ledge lengthening and the other is for thickening (Figure 6(a)). Li et al. proposed the growth mechanisms of tapered $\mathrm{ZnO}$ nanowire arrays with the aids of step velocity and radial growth rate [27]. They mentioned only the concept of the ledge velocity and radial velocity for the tapering angle. Shi et al. proposed the lattice step ledges as preferred places for nucleation of $\mathrm{ZnO}$ by the oxidation of $\mathrm{Zn}$ on step ledges [28]. Both of them did not present the experimental data in growth rates. Based upon the conservation of mass transporting from the vapor and migrating on the surface, the ledge velocity for a multiplegrowth step condition is formulated as [25]

$$
\begin{aligned}
v_{\text {ledge }} & =\frac{\sqrt{2}\left(C_{\infty}-C_{e}\right) \lambda}{N^{*} \cdot \tau} \times \tanh \left(\frac{d}{\sqrt{2} \lambda}\right) \\
& =\frac{\sqrt{2}(S-1) Z_{e} \lambda}{N^{*}} \times \tanh \left(\frac{d}{\sqrt{2} \lambda}\right),
\end{aligned}
$$

where $C_{\infty}$ is the concentration of reactants in the gas phase far away from the growing interface, $C_{e}$ the equilibrium concentration at vapor-solid interface, $C_{i}$ the interface concentration, $C_{p}$ the concentration of $\mathrm{ZnO}$ crystal, $d$ the distance between steps, $Z_{e}$ the stream of colliding reactants per unit time in equilibrium on interfaces, $\lambda$ the mean diffusion distance between adsorption and evaporation, $N^{*}$ the number of sites per unit area on crystal surface, $\tau$ the mean time of stay for adatoms, $S$ the supersaturation $\left(C_{\infty} / C_{e}\right)$, and $C_{e}$ defined as $Z_{e} \cdot \tau$. In the ledge mechanism, the adsorbed reactant vapor will evaporate if it resides far away from steps. Although this equation is derived from a 


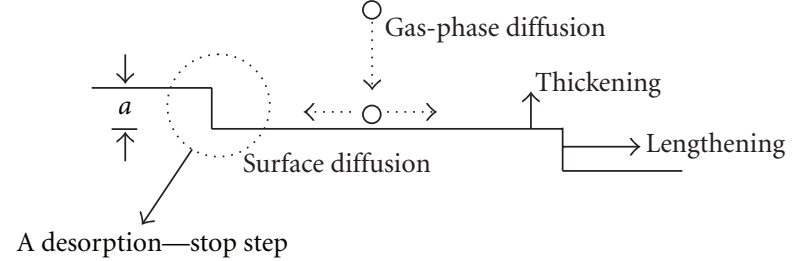

(a)

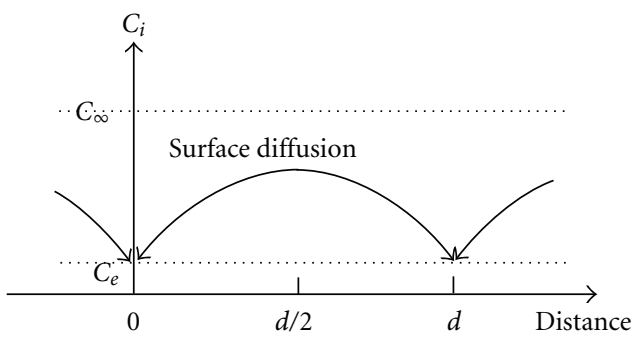

(b)

FIgURE 6: (a) Schematic configuration of the vapor-phase growth of $\mathrm{ZnO}$ rods via the combination of the ledge mechanism and diffusion processes, which involves the surface diffusion-controlled mechanism nearby the growing steps and the gas phase diffusioncontrolled mechanism nearby the solid-vapor interface. The concentration profile for the surface diffusion-controlled growth mechanism is shown in (b).

well-known model, its utilization together with the growth data of one-dimensional crystals is rare.

Based upon the two-dimensional nucleation, $d$ is proportional to the critical size of nuclei and inversely proportional to the formation energy of the nanorods $\left(\Delta G_{f}\right) . \Delta G_{f}$ related to the free energies of the gas-phase state and the equilibrium solid state is proportional to the $\mathrm{RT} \cdot \ln \left(C_{\infty} / C_{e}\right)$. Therefore, the step spacing can be related to supersaturation of $(S-1)$ as shown in (2) provided $\left(C_{\infty}-C_{e}\right) \ll C_{e}$ in a dilute gas phase [25]:

$$
\begin{aligned}
d \propto \frac{1}{\Delta G_{f}} & =\frac{1}{\mathrm{RT} \cdot \ln \left(C_{\infty} / C_{e}\right)} \\
& \approx \frac{1}{\mathrm{RT} \cdot\left(C_{\infty}-C_{e}\right) / C_{e}} \\
& =\frac{1}{\mathrm{RT} \cdot(S-1)} .
\end{aligned}
$$

Under a constant reactant flux, the apparent flux at the growth front of crystal gradually becomes increased because the crystal becomes longer. Therefore, one assumption is made here to have supersaturation $(S-1)$ proportional to $t^{1 / 2}$, that is, $(S-1)=k_{1} t^{1 / 2}$ with $k_{1}$ a constant.

Our two systems with completely different behaviors in growth rates are discussed in the following sections with the viewpoint of kinetic formulation for the growth stage.

\subsubsection{ZnO Nanorods Grown on Sn/Ni-Coated Substrates.} These ZnO NRs grow faster at the axial direction but do not increase its dimension in diameter. The $\mathrm{ZnO}$ growth is confined by the candlestick-like nuclei to grow only in the axial direction (Figure 4(a)). It is assumed that the axial growth of smooth growing fronts of $\mathrm{ZnO} \mathrm{NRs}$ is assisted by the "ledge mechanism." These ledges form on nuclei and on the flat-end top surface under a supersaturation growth condition in order to initiate the two-dimensional nucleation and growth processes. With the ledge growth mechanism, the lengthening rate can be expressed as

$$
\frac{d \ell}{d t_{\mathrm{axial}}^{\mathrm{Sn} / \mathrm{Ni}}}=\frac{a}{d} \times v_{\text {ledge }}
$$

As higher strain energy is embedded in the $\mathrm{Zn}$ vaporcovering $\mathrm{Sn} / \mathrm{Ni}$ layer, the ledges formed on the nuclei under supersaturation are a lot and their step spacing of $d$ is quite smaller than the mean diffusion distance. With the condition of $d \ll \lambda$, (1) can be simplified as

$$
\begin{aligned}
\frac{d \ell}{d t_{\mathrm{axial}}^{\mathrm{n} / \mathrm{Ni}}} & \approx \frac{a}{d} \times \frac{\sqrt{2}(S-1) Z_{e} \lambda}{N^{*}} \times\left(\frac{d}{\sqrt{2} \lambda}\right) \\
& =\frac{a \cdot Z_{e}}{N^{*}}(S-1) \\
& \approx \frac{a \cdot Z_{e}}{N^{*}} \cdot k_{1} \sqrt{t} .
\end{aligned}
$$

With this derivation, the axial rate of the $\mathrm{Sn} / \mathrm{Ni}$ system is proportional to $t^{1 / 2}$, which is consistent with our experimental data in Figure 4(c).

As for a nil growth rate in diameter, it indicates the reactant vapor can only form nuclei on the flat-end cones. The nucleation on the smooth sides of hexagonal cones is difficult. The accommodation factor of reactant vapors for this system except on the flat-end top surface is almost negligible. The inability to build a radial rate can be related to the taller nuclei with steep edges, which is difficult to build the desorption-stop steps (Figure 6(a)) on nuclei. The desorption-stop step is the step in the ledge mechanism with the emphasis on its function to hold the adatoms. The adatoms without the desorption-stop steps cannot stick to that interface and will slip away or desorb from substrates.

Here, we need to clarify that the higher supersaturation due to larger strain energy can nucleate the growth steps with a short spacing (2). From the $\mathrm{Sn} / \mathrm{Ni}$ system with a nil radial growth rate, we understand that supersaturation in vapor surrounding NRs is not helpful in building the heterogeneous nuclei on the NR sides. This behavior is also applied to the other system due to the same reactant flux. To differentiate these systems, the types of the desorption-stop steps on nuclei is important.

4.3.2. ZnO Nanorods Grown on Sn/In-Coated Substrates. These $\mathrm{ZnO}$ NRs have grown with a linearly increasing rate in the axial direction (Figure 4(c)) in addition to a constant thickening rate (Figure 4(d)). Our NR lengthening is analyzed with the similar equation of (1), but the condition becomes $d \gg \lambda$ and $\tanh (d / \sqrt{ } 2 \cdot \lambda) \approx 1$. This hypothesis can 
be supported by the smallest strain energy in the buffer layer. Therefore, (1) for the axial growth rate becomes

$$
\begin{aligned}
\frac{d \ell}{d t_{\mathrm{axial}}^{\mathrm{Sn} / \mathrm{ln}}} & \approx \frac{a}{d} \times \frac{\sqrt{2}(S-1) Z_{e} \lambda}{N^{*}} \times 1 \\
& =k_{2} a \mathrm{RT}(S-1) \times \frac{\sqrt{2}(S-1) Z_{e} \lambda}{N^{*}} \\
& =k_{3}(S-1)^{2} \\
\frac{d \ell}{d t_{\mathrm{axial}}^{\mathrm{Sn} / \mathrm{In}}} & \approx k_{3}\left(k_{1} \cdot t^{1 / 2}\right)^{2}=k t,
\end{aligned}
$$

where $k, k_{2}$, and $k_{3}$ are the proportional constants. With this derivation, the axial rate of the $\mathrm{Sn} / \mathrm{In}$ system is proportional to $t$, which is consistent with the growth rate data in Figure $4(\mathrm{c})$.

Our NRs were thickened at the same time of the axial growth but with a slower rate. In order to increase the NR diameter, new absorbing adatoms need to arrive on the growing-stop steps of nuclei. Due to the smaller strain energy or the larger step distance, the attachment of reactant adatoms on the steps of nuclei is more difficult. In this situation, the $\mathrm{ZnO}$ growth on the desorption-stop steps of nuclei becomes a rate-determining factor, the NR thickening is controlled by the reactant reactions on the buffer layercovering substrates, or the radial growth is an surface diffusion-controlled process (Figure 6(b)). For the interfacecontrolled growth, the growth rate or the thickening rate, proportional to the difference in chemical potentials $(\Delta \mu)$ of reactions at interface and at equilibrium or approximately to the off-balance concentration $\left(C_{i}-C_{e}\right)$ at moving interfaces (Figure 6(b)), can be expressed as

$$
\begin{aligned}
v_{\text {radial }}^{\mathrm{Sn} / \mathrm{In}} & =M \cdot(\text { force })=M \cdot \frac{\Delta \mu}{V_{m}} \\
& =\frac{M \mathrm{RT}}{V_{m}} \cdot \ln \left(\frac{C_{i}}{C_{e}}\right) \\
& \approx \frac{M \mathrm{RT}}{V_{m}} \cdot \frac{C_{i}-C_{e}}{C_{e}},
\end{aligned}
$$

where $M$ is the interface mobility, $C_{i}$ is the concentration between steps, and $V_{m}$ the molar volume of materials. Therefore, the thickening rate of the $\mathrm{Sn} / \mathrm{In}$ system is almost constant, which is consistent with the experimental data in Figure 4(d).

Our proposed growth formulations are applied only for $1 \mathrm{D} \mathrm{ZnO}$ grown by a vapor-solid mechanism. For the growth via a vapor-liquid-solid process, the diffusion in liquid droplets becomes the rate-determining step for lengthening as the wire diameter is determined by the catalyst size [29].

Growth behaviors of one-dimensional $\mathrm{ZnO}$ nanorods grown with a vapor-solid process are determined by the nucleus states of the buffer layer on substrates. With different surface modifications to generate different residual stress states in the buffer layers, the nucleation and growth behaviors for the rod growth become different, which reveal in the different growth behaviors in the axial and radial directions. With the successful equation formulations applied to different growth modes by using the basic kinetic model for crystals growing from vapor, the $\mathrm{ZnO}$ growth behaviors can be better elucidated and understood. Although some assumptions have been made and some considerations may not be complete, this work is trying to curve fit the experimental data with rate equations and to find the relevance between the axial and radial growth behaviors. In the $\mathrm{Sn} / \mathrm{Ni}$ system, the $\mathrm{ZnO}$ growth occurs with the aid of the ledges on the flat-end top surface of the candlestick-like nuclei. No rod thickening is caused by the difficulty in the attachment of reactants on the side surface of camdlestick-like nuclei. For the $\mathrm{Sn} / \mathrm{In}$ system, growths in the axial and radial directions simultaneously occur. Their lengthening provided by a ledge mechanism is determined by the step configuration. Their thickening is attributed to the attachment of reactant vapors to steps on nuclei through a surface diffusion-controlled process.

\section{Conclusions}

Vertically aligned $\mathrm{ZnO}$ nanorods were successfully grown on the bilayer catalyst-covered sapphire substrates with a length of $30 \pm 10 \mu \mathrm{m}$ and a diameter of $110 \pm 25 \mathrm{~nm}$ by thermal evaporation at $700^{\circ} \mathrm{C}$ for $2 \mathrm{~h}$ in the atmospheres of oxygen and nitrogen. The bilayer catalysts included $\mathrm{Sn} / \mathrm{Ni}$ and $\mathrm{Sn} / \mathrm{In}$ with the top and bottom layers prepared by sputtering and spin coating, respectively. $\mathrm{Sn} / \mathrm{Ni}$ system shows a promising potential to grow vertically aligned $\mathrm{ZnO}$ nanorod arrays with a good ultraviolet emission from the regular and candlesticklike pyramid nuclei, which is aided by the strain energy built in the underlining catalyst layer. Without the pyramidal nuclei, slightly inclined nanorods in the Sn/In sytem were grown. The kinetic data of the growth rates in axial and radial directions for the $\mathrm{Sn} / \mathrm{Ni}$ and $\mathrm{Sn} / \mathrm{In}$ systems can be successfully curve fitted, correlated, and interpreted by kinetic equations, based upon the ledge mechanism for the vapor-solid crystal growth and diffusion kinetics.

\section{Acknowledgment}

The authors acknowledge the financial support by National Science Council under Grant No. 101-2221-E-011-046.

\section{References}

[1] H. J. Fan, B. Fuhrmann, R. Scholz et al., "Well-ordered ZnO nanowire arrays on GaN substrate fabricated via nanosphere lithography," Journal of Crystal Growth, vol. 287, no. 1, pp. 3438,2006

[2] X. Wang, C. J. Summers, and Z. L. Wang, "Large-scale hexagonal-patterned growth of aligned $\mathrm{ZnO}$ nanorods for nanooptoelectronics and nanosensor arrays," Nano Letters, vol. 4, no. 3, pp. 423-426, 2004.

[3] D. S. Kim, R. Ji, H. J. Fan et al., "Laser-interference lithography tailored for highly symmetrically arranged $\mathrm{ZnO}$ nanowire arrays," Small, vol. 3, no. 1, pp. 76-80, 2007.

[4] L. Wang, X. Zhang, S. Zhao, G. Zhou, Y. Zhou, and J. Qi, "Synthesis of well-aligned $\mathrm{ZnO}$ nanowires by simple physical 
vapor deposition on $c$-oriented $\mathrm{ZnO}$ thin films without catalysts or additives," Applied Physics Letters, vol. 86, no. 2, Article ID 024108, 3 pages, 2005.

[5] A. Umar, B. Karunagaran, E. K. Suh, and Y. B. Hahn, "Structural and optical properties of single-crystalline $\mathrm{ZnO}$ nanorods grown on silicon by thermal evaporation," Nanotechnology, vol. 17, no. 16, pp. 4072-4077, 2006.

[6] P. X. Gao, Y. Ding, and Z. L. Wang, "Crystallographic orientation-aligned $\mathrm{ZnO}$ nanorods grown by a tin catalyst," Nano Letters, vol. 3, no. 9, pp. 1315-1320, 2003.

[7] Y. Ding, P. X. Gao, and Z. L. Wang, "Catalyst-nanostructure interfacial lattice mismatch in determining the shape of VLS grown nanowires and nanobelts: a case of $\mathrm{Sn} / \mathrm{ZnO}$," Journal of the American Chemical Society, vol. 126, no. 7, pp. 2066-2072, 2004.

[8] D. H. Kuo and B. J. Chang, "From preannealing of bilayer catalysts to explore the growth micromechanisms of $\mathrm{ZnO}$ nanorods," Crystal Growth and Design, vol. 10, no. 2, pp. $977-$ 982, 2010.

[9] D. H. Kuo, J. F. Fang, R. S. Chen, C. A. Chen, and Y. S. Huang, "ZnO nanomaterials grown with Fe-based catalysts," Journal of Physical Chemistry C, vol. 115, no. 25, pp. 12260-12268, 2011.

[10] D.-H. Kuo and B.-J. Chang, "Growth behaviors of $\mathrm{ZnO}$ nanorods grown with the Sn-based bilayer catalyst-covered substrates," Journal of Nanomaterials, vol. 2011, Article ID 603098, 9 pages, 2011.

[11] D.-H. Kuo, J.-Y. He, and Y.-S. Huang, "Synthesis of vertically aligned $\mathrm{ZnO}$ nanorods on Ni-based buffer layers using a thermal evaporation process," Journal of Electronic Materials, vol. 41, no. 3, pp. 451-456, 2012.

[12] S. H. Park, S. H. Kim, and S. W. Han, "Growth of homoepitaxial $\mathrm{ZnO}$ film on $\mathrm{ZnO}$ nanorods and light emitting diode applications," Nanotechnology, vol. 18, no. 5, Article ID 055608, 2007.

[13] S. C. Lyu, Y. Zhang, H. Ruh et al., "Low temperature growth and photoluminescence of well-aligned zinc oxide nanowires," Chemical Physics Letters, vol. 363, no. 1-2, pp. 134-138, 2002.

[14] E. M. Wong and P. C. Searson, "ZnO quantum particle thin films fabricated by electrophoretic deposition," Applied Physics Letters, vol. 74, no. 20, pp. 2939-2941, 1999.

[15] V. Srikant and D. R. Clarke, "On the optical band gap of zinc oxide," Journal of Applied Physics, vol. 83, no. 10, pp. 54475451, 1998.

[16] W. I. Park, G. C. Yi, M. Kim, and S. J. Pennycook, "ZnO nanoneedles grown vertically on Si substrates by non-catalytic vapor-phase epitaxy," Advanced Materials, vol. 14, no. 24, pp. 1841-1843, 2002.

[17] X. Q. Meng, D. X. Zhao, J. Y. Zhang et al., "Growth temperature controlled shape variety of $\mathrm{ZnO}$ nanowires," Chemical Physics Letters, vol. 407, no. 1-3, pp. 91-94, 2005.

[18] H. Tang, J. C. Chang, Y. Shan et al., "Growth mechanism of $\mathrm{ZnO}$ nanowires via direct $\mathrm{Zn}$ evaporation," Journal of Materials Science, vol. 44, no. 2, pp. 563-571, 2009.

[19] G. Shen, Y. Bando, B. Liu, D. Golberg, and C. J. Lee, "Characterization and field-emission properties of vertically aligned $\mathrm{ZnO}$ nanonails and nanopencils fabricated by a modified thermal-evaporation process," Advanced Functional Materials, vol. 16, no. 3, pp. 410-416, 2006.

[20] D. C. Kim, S. K. Mohanta, and H. K. Cho, "Vertically aligned ultraslim zno nanowires formed by homobuffer: growth evolution and emission properties," Crystal Growth and Design, vol. 9, no. 11, pp. 4725-4729, 2009.

[21] F. C. Tsao, J. Y. Chen, C. H. Kuo et al., "Residual strain in $\mathrm{ZnO}$ nanowires grown by catalyst-free chemical vapor deposition on GaN/sapphire (0001)," Applied Physics Letters, vol. 92, no. 20, Article ID 203110, 3 pages, 2008.

[22] W. Mai, P. Gao, C. Lao et al., "Vertically aligned $\mathrm{ZnO}$ nanowire arrays on GaN and $\mathrm{SiC}$ substrates," Chemical Physics Letters, vol. 460, no. 1-3, pp. 253-256, 2008.

[23] H. Cui, G. Eres, J. Y. Howe et al., "Growth behavior of carbon nanotubes on multilayered metal catalyst film in chemical vapor deposition," Chemical Physics Letters, vol. 374, no. 3-4, pp. 222-228, 2003.

[24] H. J. Fan, F. Fleischer, W. Lee et al., "Patterned growth of aligned $\mathrm{ZnO}$ nanowire arrays on sapphire and GaN layers," Superlattices and Microstructures, vol. 36, no. 1-3, pp. 95-105, 2004.

[25] R. H. Doremus, In Rates of Phase Transformation, Academic Press, Orlando, Fla, USA, 1985.

[26] D. A. Porter and K. E. Eastering, In Phase Transformations In Metals and Alloys, CRC Press, 2nd edition, 1992.

[27] S. Li, X. Zhang, and L. Zhang, " $\mathrm{Sb}_{2} \mathrm{O}_{3}$-induced tapered $\mathrm{ZnO}$ nanowire arrays: the kinetics of radial growth and morphology control," Journal of Physical Chemistry C, vol. 114, no. 23, pp. 10379-10385, 2010.

[28] J. Shi, S. Grutzik, and X. Wang, "Zn cluster drifting effect for the formation of $\mathrm{ZnO} 3 \mathrm{D}$ nanoarchitecture," ACS Nano, vol. 3, no. 6, pp. 1594-1602, 2009.

[29] D. H. Kuo and M. Y. Su, "Growth and kinetic modeling of $\mathrm{Fe}(\mathrm{CO})_{5}$-catalyzed carbon nanotubes grown by chemical vapor deposition," Journal of the Electrochemical Society, vol. 153, no. 4, pp. J21-J25, 2006. 

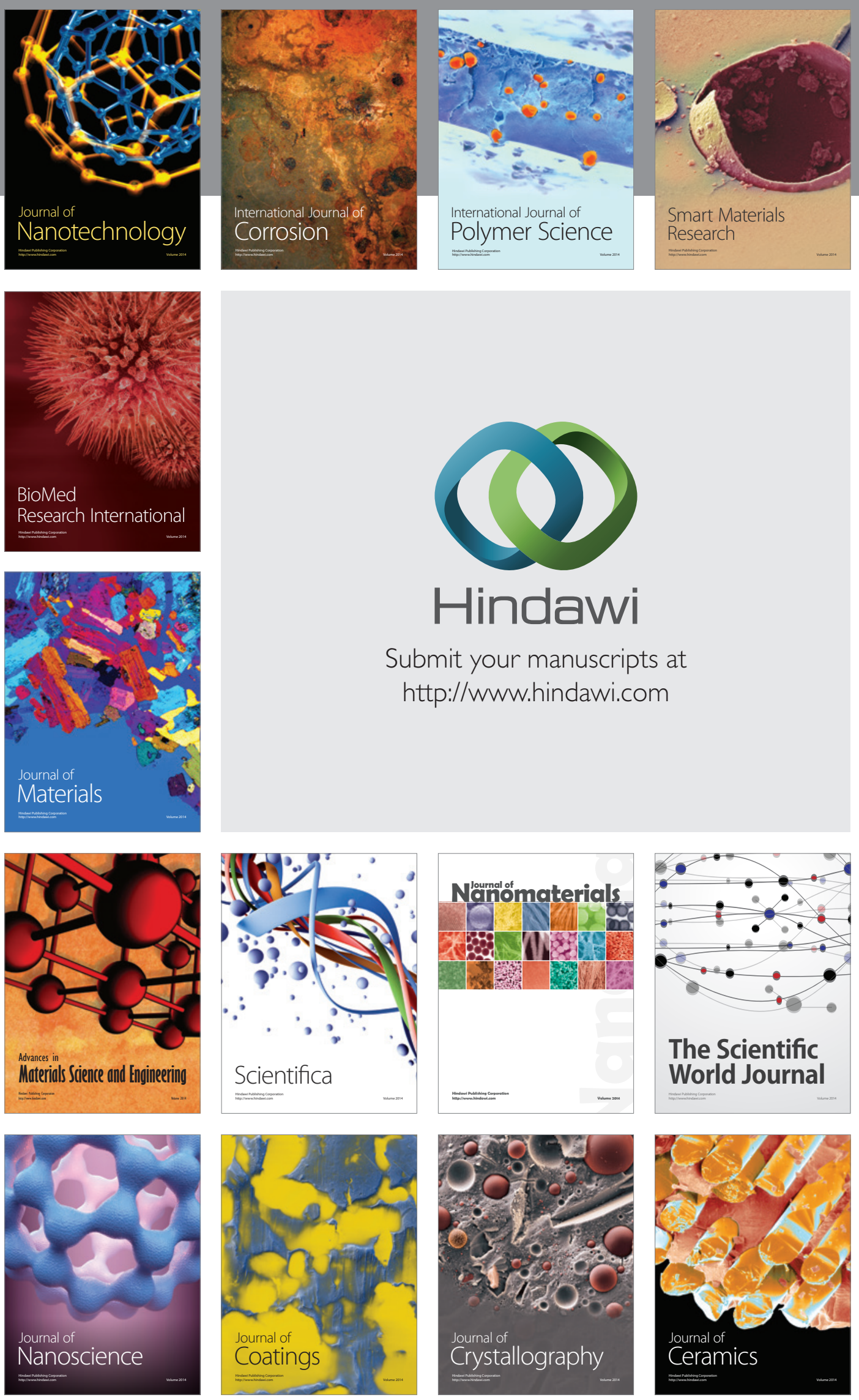

The Scientific World Journal

Submit your manuscripts at

http://www.hindawi.com

\section{World Journal}

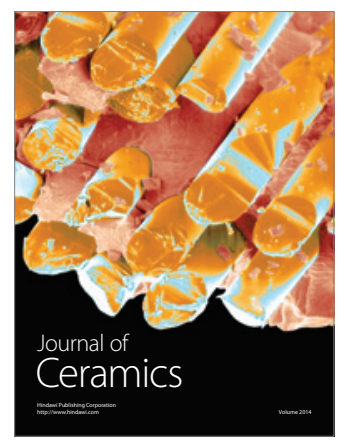

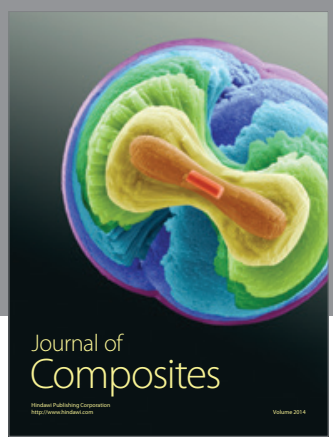
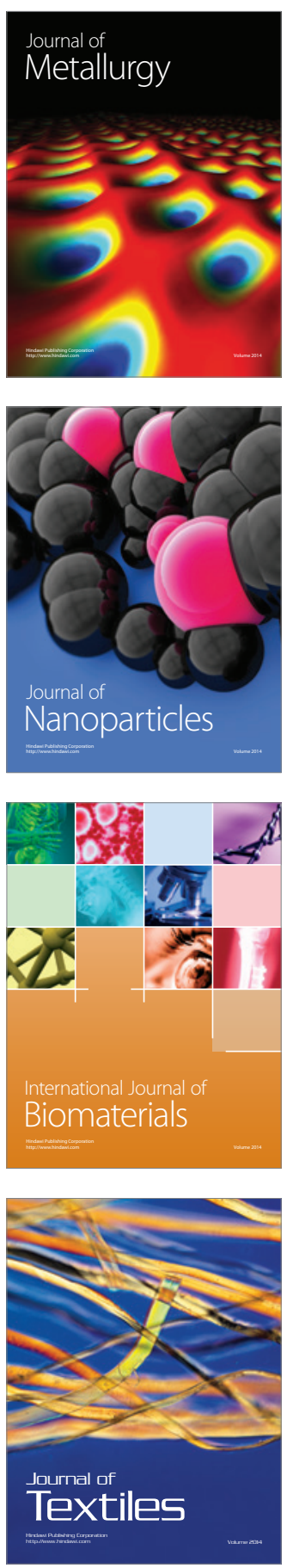